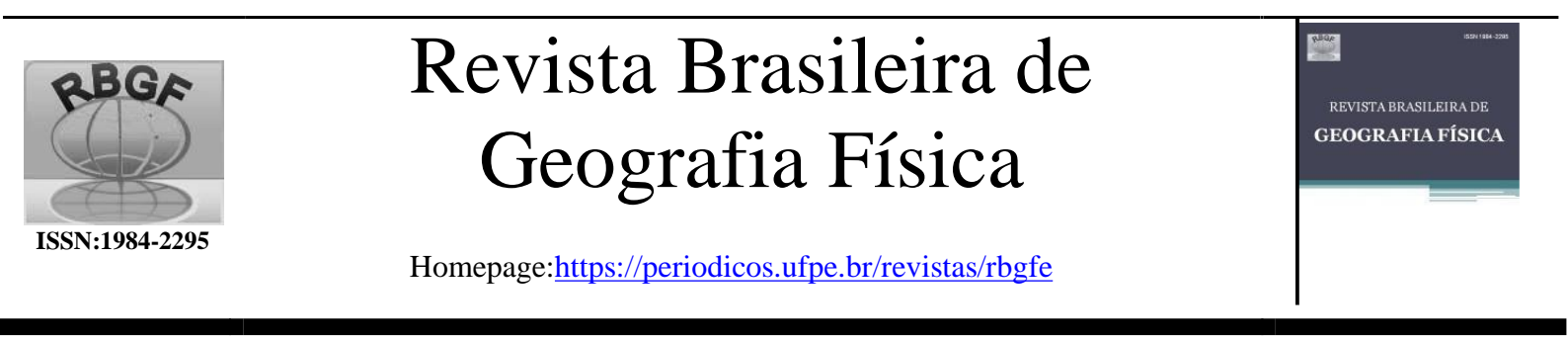

\title{
Avaliação de técnicas para obtenção do NDVI MSG de qualidade para monitoramento da superfície do solo ${ }^{1}$
}

\begin{abstract}
Carlos Roberto da Silveira Junior ${ }^{1}$, Laerte Guimarães Ferreira Junior ${ }^{2}$, Bernardo Barbosa da Silva ${ }^{3}$ 1. Doctor in Environmental Sciences. Instituto Federal de Goiás. Rua 75, $n^{\circ}$ 46. Centro, 74055-110. Goia nia - GO, Brazil. E-mail: carlos.junior@ifg.edu.br (corresponding author). 2. Doctor in Remote Sensing. Instituto de Estudos SócioAmbientais. Campus Samambaia, Alameda Palmeiras s/n, 74001-970, Goiânia - GO, Brasil. Universidade Federal de Goiás. E-mail: lapig.ufg@gmail.com. 3. Doctor in Civil Engineering - Area of Hydric Resources. Centro de Tecnologias e Recursos Naturais. Av. Aprígio Veloso, n 882. Bairro Universitario, 58.109-970, Campina Grande, Paraíba, Brasil. Universidade Federal de Campina Grande.E-mail: bernardo.silva @ufcg.edu.br.
\end{abstract}

Artigo recebido em 26/10/2019 e aceito em 20/07/2020

\section{R E S U M O}

Os satélites geoestacionários representam uma alternativa de alta resolução temporalpara o monitoramento da superfície do solo em comparação com os satélites em órbita polar. Entretanto, em ângulos de visão elevados, alguns fatores influenciam a refletância da superfície, diminuindo a qualidade dos índices de vegetação, sendo importante o uso de técnicas de correção atmosférica e geométrica. Este artigo tem como objetivo avaliar dados do satélite de órbita geoestacionária MSG (Meteosat Second Generation) para obter o índice de vegetação de qualidade NDVI (Normalized Difference Vegetation Index) em regiões de alto ângulo de visão, tendo como área de estudo o estado de Goiás, no Brasil. As imagens MODIS (MODerate Image Spectroradiometer) foram utilizadas como referência para identificar características temporais das observações quanto à composição do produto e a valiar o desempenho das técnica a valia das. O período de estudo foi de 2013 a 2015. Como resultado, o NDVI MSG, obtido das $10 \mathrm{~h}$ às $12 \mathrm{~h}$, horário local, fornece uma imagem com 95\% de cobertura de pixel, em 12 dias, enquanto o MOD09 a obtém em 16 dias. A correção geométrica é um ajuste fino que não apresentou maior correlação de dados. Por outro lado, a correção atmosférica mantém a correlação dos da dos e aumenta o va lor do NDVI, a proximando -o do va lor do NDVI MODIS. Executando uma a plicação PCA (Principal Component Analysis) usando a técnica de classificação k-means não supervisionada, o NDVI MSG forneceu resultados superiores em comparação ao MODIS, demonstrando o potencial de dados geoestacionários para o monitoramento da superfície do solo.

Palavras-chave: MSG, NDVI, 6S, BRDF, satélite de órbita geoestacionária.

\section{Evaluation of techniques for improvement of NDVI MSG quality for soil surface monitoring}

\section{A B S T R A C T}

Geostationary satellites represent a high temporal resolution alternative for ground surface monitoring compared to polar orbiting satellites. However, at high viewing angles, some factors influence surface reflectance, decreasing the quality of vegetation indices, reason why it is important to use atmospheric and geometric correction techniques. This article aims to evaluate data from the MSG (Meteosat Second Generation) geostationary orbit satellite to obtain the NDVI (Normalized Difference Vegetation Index) quality vegetation index in high viewing angle regions, having as study area the state of Goiás, in Brazil. MODIS (MODerate Image Spectroradiometer)images were used as a reference to identify temporal characteristics of the observations for product composition and to evaluate the performance of the evaluated techniques. The study database period was 2013-2015. As a result, the NDVI MSG, obtained from 10:00 to 12:00 local time, provides an image with 95\% pixel coverage, within 12 days, while MOD09 gets it within 16 days. Geometric correction is a fine-tuning that did not present increased correlation of data. On the other hand, atmospheric correction maintains the correlation of the data and increases the value of NDVI, bringing it closer to the NDVI MODIS value. Performing a PCA (Principal Component Analysis) application using the unsupervised k-means classification technique, NDVI MSG provided superior results compared to MODIS, demonstrating the potential of geostation ary data for soil surface monitoring.

Keywords: MSG, NDVI, 6S, BRDF, geostationary orbit satellite.

${ }^{1}$ Article extracted from Thesis. 
Revista Brasileira de Geografia Física, Vol. 13, n. 05 (2020) 2304-2318.

\section{Introduction}

Ground cover monitoring using remote sensing data allows the understanding of surface processes at different spatial and temporal scales. New generations of geostationary orbiting satellites present spectral bands that allow surface monitoring with low spatial resolution $(500 \mathrm{~m}$ to 3 $\mathrm{km})$ and high temporal resolution (10 to 25 minutes). This has been made possible from the MSG (Meteosat Second Generation) series and, more recently, obtaining global coverage with the new Himawari and GOES (Geostationary Operational Environmental Satellite) series.

Among MSG series satellites, Meteosat10, from the SEVIRI (Spinning Enhanced Visible and InfraRed Imager) sensor, provides images with spatial resolution of $3 \mathrm{~km}$ and temporal resolution of 15 minutes with coverage over Europe, Africa and part of South America. Being efficient for monitoring vegetation from the NDVI (Normalized Difference Vegetation Index) index, which corresponds to the normalized difference between the near infrared (NIR) and red (RED) spectral bands (Tucker, 1979), for regions Africa, presenting a high spatial correlation with polar satellite data (Sarr and Lacaze, 2008; Fensholt et al., 2011), being used in the analysis and behavior of vegetation stress (Barbosa et al., 2019) and estimates of phenology (Julien et al., 2018).

The high temporal resolution of Meteosat10 may represent a relevant advantage when considering that polar orbiting satellites face the challenge of generating images free of atmospheric contamination and clouds, requiring several observations over days or weeks to generate an image of composition (Fensholt et al., 2006; Fensholt et al., 2011; Solano et al. 2015). On the other hand, geostationary orbiting satellites can observe the Earth's surface during the day with greater frequency and, through windows in the cloud cover, obtain composition images with a shorter interval of days (Fensholt et al., 2006; Miura et al., 2019). Equally, due to the high temporal resolution of Meteosat-10, opportunities arise to address processes that occur in crops, such as the duration and intensity of photosynthetic activity and understanding of phenology, which previously could not be measured (Fensholt et al., 2011).

However, in regions considered to have a high angle of view (eg $50^{\circ}$ to $75^{\circ}$ ), the MSG vegetation indices are less used for soil surface monitoring due factors that decrease the reflectance measurement quality of the orbital sensors (Silveira et al., 2019) such as: a) increasing the surface field of view, which results in increased correlation of neighboring pixels (Cracknell, 1998); b) the increase of the optical path of the photons, which causes the increase of the influence of atmospheric conditions on the surface reflectance (Julien et al., 2018); c) the increase of the shadows of the surface bodies and clouds due to observation geometry, which causes the variation of the NDVI value during the day (Roujean et al, 1992).

Thus, it is necessary that these characteristics are correctly understood and modeled, in order to obtain a better quality indicator, like used in polar satellite as MODIS (MODerate Image Spectroradiometer) that use geometric and atmospheric correction to produce NDVI product (Solano et al., 2015). Furthermore, its possibility to weigh the potential given and the application possibilities the use of NDVI images from Meteosat-10 requires and, with this, recognizes the real potential of data from satellites or geostationary orbitals for the environmental monitoring of the land area. Recently similar study was did for Himawari-8 in China study areas (Seong et al., 2020).

This paper aims to evaluate data from Meteosat-10 geostationary orbit satellite to obtain NDVI vegetation index of quality in regions of high angle of view, having the state of Goiás, Brazil, as area of study. The MODIS images as used like a reference to identify temporal characteristics of observations for product composition and to evaluate the performance of the evaluated techniques. The study database period was 2013-2015.

The hypothesis is that the geostationary orbit satellite Meteosat-10 has a high angle of view for Brazil, which causes greater geometric (Fensholt et al., 2006) and atmospheric (Vermote et al., 1997) influence over the reflectance of the surface; then, the use of geometric correction techniques (Proud et al., 2014), atmospheric (Kotchenova and Vermote, 2007; Proud et al., 2010) tends to increase the correlation between biophysical indicators derived from geostationary and polar orbit systems. 
Revista Brasileira de Geografia Física, Vol. 13, n. 05 (2020) 2304-2318.

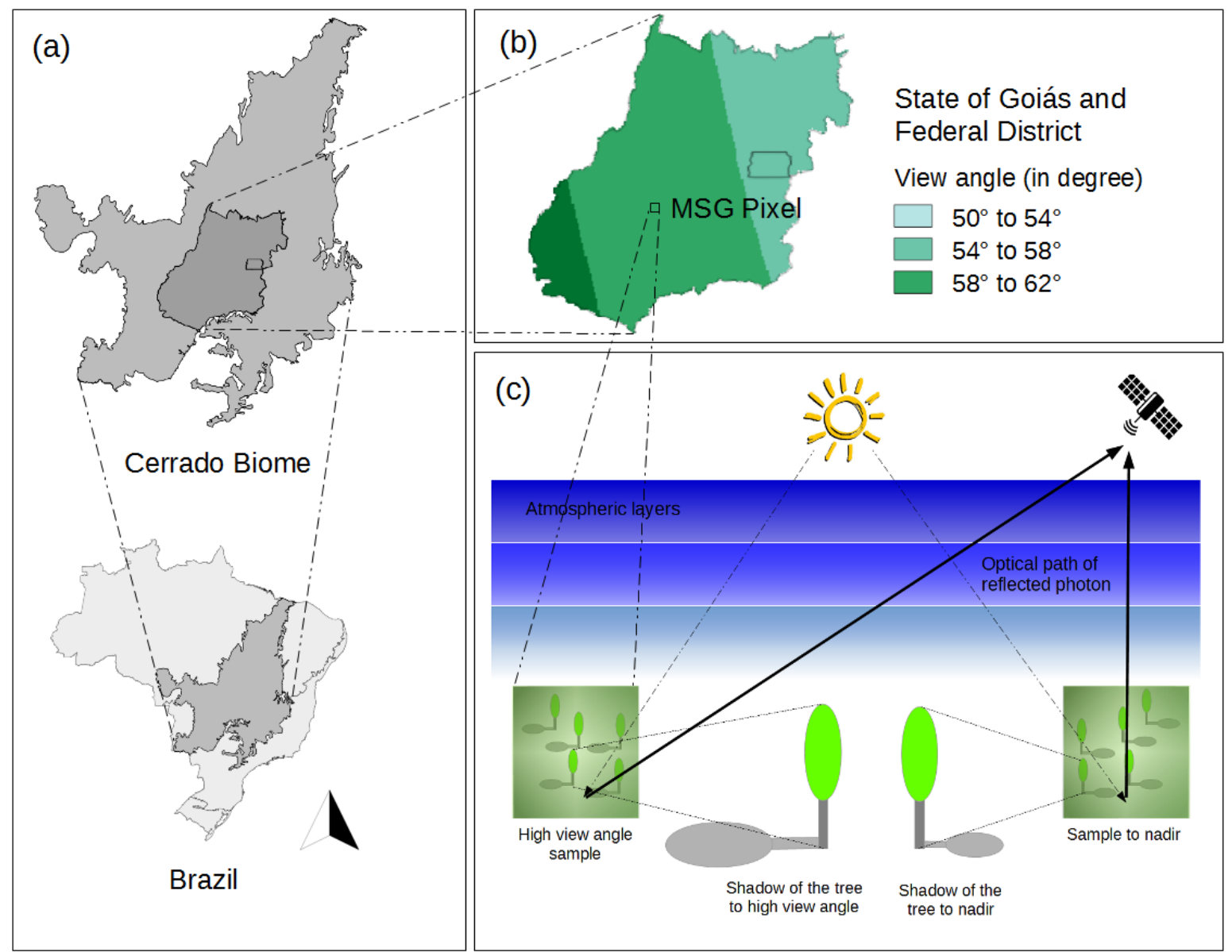

Figure 1. Study area, as follows: the state of Goiás, including the Federal District, within the Cerrado Biome, in Brazil (a); MSG viewing angle for the study area (b); illustration of differences between a nadir pixel and high angle of view (c).

\section{Materials and methods}

The area of study was the state of Goiás, including the Federal District, which is almost entirely within the Brazilian Cerradobiome (Figure 1 -a), having only a small part to the southeast as Atlantic Forest. It has a high viewing angle for the MSG, ranging from 50 to $65^{\circ}$ (Figure 1 -b), wherein these conditions the optical path of the pixel compared to nadir pixel increases, which increases influences of atmospheric conditions, as well as the shading of the surface bodies, influencing, therefore, the surface reflectance measure as shown in the illustration (Figure 1-c).

The climate is characterized as semi-humid tropical in big part of state and humid in the southwest, with two defined seasons: humid summer and dry winter, with monsoon characteristics, $80 \%$ of the rains fall from November to March, while from May to September the weather is dry with little rainfall (IBGE, 2002), with the transition months being April and October, respectively, from rainy season to dry and dry to rainy season. Brazilian Cerrado is devoid of original vegetation in a large part of its territory
(MMA, 2015), and the cerrado in Goiás state has been largely converted into agriculture and pasture, and this conversion has important implications for climate changes and changes in carbon flows between the atmosphere and the Earth's surface (Ratana et al., 2005).

To processing data, initially, the daily observation interval was defined for obtaining the daily NDVI MSG, according to established technical criteria. The product was then used for analysis and definition of the day interval to obtain the NDVI MSG composition. In the next step, the daily NDVIMSG obtained wasused for processing atmospheric correction and geometric correction techniques. The results of this processing were evaluated in the next step, thus, defining which techniques were used to obtain the quality NDVI MSG. The last step was related to the application of the product obtained in order to identify the capacity for seasonality abstraction and land use classification. 
Revista Brasileira de Geografia Física, Vol. 13, n. 05 (2020) 2304-2318.

\section{Obtaining the daily NDVI MSG}

The MSG has a 15-minute time resolution providing images throughout the day. However, for the analysis, the interval from 10:00 to 12:00 was chosen because it presents less variation in the zenith and azimuthal angles and greater illumination, resulting in less variation in the NDVI value (Fensholt et al., 2006). Then, data availability for the area of study was evaluated through the analysis of images of the average of the samples per pixel during the month, as well as by plotting coverage percentages at different day intervals (1 to 20 days).

For these processing, data from MSG type HRIT (High-Rate Image Transmission) level 1.5 were used, georeferenced and radiometrically preprocessed images with spatial resolution of 3 $\mathrm{km}$. In order to obtain NDVI MSG without cloud cover, CLM (CLoud Mask) product was used. The NDVI MOD09 was obtained from the daily product MOD09GA which provides the daily surface reflectance (L2G) with spatial resolution of $500 \mathrm{~m}$, to obtain its MOD09 cloud mask band provide pixel quality (cloud state) (Kotchenova and Vermote, 1999). The python language was used to processing data involved in the study, having as base tool for image processing the GDAL library (Geospatial Data Abstraction Library) (GDAL, 2020), were are used libraries and algorithms developed in research related to geometric and atmospheric correction (Wilson, 2013; GomesDans, 2015).

\section{Geometric correction}

Geometric correction allows to remove the influence of scene geometry on a data series of one pixel (Wanner et al., 1995), calculating the angular effects of BRDF (Bidirectional Reflectance Distribution Function) allows a more accurate data comparison between different locations and times of the year (Proud et al., 2014). This calc is made from linear models that differ in the detail with which they describe the physical processes responsible for light diffusion (Wanner et al., 1995). The semiempirical models of kerneldriven represents the surface through the linear assumption of a set of kernel that complement each other to represent the surface reflection characteristics (isometric, volumetric and geometric) (Roujean et al., 1992). In this study, Ross-Thick (it models bodies with large volume of leaves on the surface) and Li-Sparse (it models areas with sparse distribution of bodies) kernel were used in the geometric correction processing of the NDVI MSG product, similar to the kernel used in the algorithm of the
Albedo MODIS product (Wanner et al., 1995; Schaaf et al., 2002).

As an alternative to the occurrence of calculation failures, due to large variations in lighting angles, or few samples on the day, parameters obtained on the previous day were used (Silveira et al., 2017). The angles representing the geometry (azimuthal and zenithal) of view and illumination were obtained from the processing algorithms provided by EUMETCAST in the Geonetcast Toolbox package (Maathuis et al., 2013), which presents spatial resolution of angles of $0.45^{\circ}$, the data being redesigned using cubic convolution and resampling to $3 \mathrm{~km}$.

\section{Atmospheric correction}

The signal measured by a satellite sensor contains a combination of atmospheric and surface contributions (Jones and Vaughan, 2010) requiring atmospheric correction of surface reflectance from computational techniques that differ in complexity and time of processing (Proud et al., 2010). The $6 \mathrm{~S}$ (Second Simulation of a Satellite Signal in the Solar Spectrum) is a radiation transfer algorithm that models atmospheric interactions with radiation from a discrete number of homogeneous layers (Vermote et al., 1997), performs well at high viewing angles (Kotchenova and Vermote, 2007), being used in the MODIS atmospheric correction algorithm (Qu et al., 2014). In order to calculate the $6 \mathrm{~S}$ correction, the 6SV1 program was used, having the Py6S library as communication interface (Wilson, 2013). In order to optimize the processing time of the 6S, LUTs (Look-Up Tables), tables composed of input values of observation angles (solar azimuthal and view angle and solar zenithal angle and view) and atmospheric conditions (water vapor, ozone and AOT (Aerosol Optical Depth )) were used and whose output values of atmospheric correction parameters for bands used (Lee et al., 2015), range values used are shown in Table 1.

Table1. Set variables and ranges for LUT (Look-

Up Table) atmospheric correction.

\begin{tabular}{lccc}
\hline \multicolumn{1}{c}{ Input parameter } & Min & Max & Gap \\
\hline View zenith angle & 55 & 65 & 2,5 \\
View azimuth angle & 100 & 110 & 2,5 \\
Sun zenith angle & 0 & 60 & 10 \\
Sun azimuth angle & 0 & 360 & 60 \\
Water vapour $\left(\mathrm{g} / \mathrm{cm}^{2}\right)$ & 0 & 0,9 & 0,1 \\
Ozone (cm-atm) & 0 & 0,36 & 0,6 \\
AOT & 0 & 0,8 & 0,1 \\
\hline
\end{tabular}

Thus, enables to calculate the reflectance of the RED and NIR for NDVI MSG with atmospheric correction (Vermote et al., 2006). The 
Revista Brasileira de Geografia Física, Vol. 13, n. 05 (2020) 2304-2318.

weather data were obtained by interpolating the daily products MOD08 and MYD08 (Hubanks et al., 2016). This method was recently used in Himawari-8 to obtain NDVI with atmospheric correction (Seong et al., 2020).

\section{Evaluation of Results}

For this, points were selected from each of the different classes of land use that make up large areas (annual agriculture, livestock and natural landscape). Four classes corresponding to the three most representative land use classes of the TerraClass 2013 map (at $3 \mathrm{~km}$ resolution) were considered, this map provide Cerrado mapping and land use, being: pasture (51\%), natural (29\%) and annual agriculture (17\%), and the remaining of the classes (eg perennial agriculture, mining, urban) was considered in the class named "others" because it is less representative (3\%) (MMA, 2015). The results were presented using composite images for each of the techniques and scatter plots and time series of pixels selected from each land use class.

\section{NDVI MSG Application}

To evaluate the potential of the NDVI MSG product, a study on the classification capacity of the area of the study using NDVI MSG and NDVI MOD13 time series from 2013 to 2015 was used. In order to reduce the noise in the images, the following sequential data preprocessing procedures were performed (Chen et. al, 2004; Almeida et al., 2015): 1) filtering of NDVI values influenced by subpixel clouds or obtained from channel with reading failure; 2) interpolation of pixels without information using time series data; 3) smoothing the time series using the Savitzky-Golay filter, that is promising noisereduction method for generating high-quality NDVI time-series data (Cao et al., 2018).

Subsequently, he applied the PCA (Principal Components Analysis) technique on the time series of NDVI MSG and NDVI MOD13, from the average values for each frame interval, resulting in images NDVI MSG and NDVI MOD13 which provide information on the annual seasonality of the area of study.

Then, in order to classify the resulting images, the three main components were applied using the unsupervised $k$-mean classification technique (Macqueen, 1967). The algorithm has been configured to use a training base of 1,000 samples, maximum number of iterations 10,000, and convergence threshold of
0.0001 . Several images were generated and visual analysis was performed to select the image, for triplicate, with the closest classification to the Terraclass 2013 map. The images were used to generate the confusion matrix and Cohen's Kappa agreement index to identify according to categorical classifications (Cohen, 1960). For these processing steps (PCA and Kmeans), QGIS (Quantum GIS) software libraries were used.

\section{Results}

As a result of the temporal resolution analysis of the data, there is a higher monthly sample average for the NDVI MSG (17.7) compared to the NDVI MOD09 (13.04). The Figure 2 shows the evaluation of the percentage coverage of the area of study in intervals of 1 to 20 days to NDVI MSG to drought (a) and precipitation (b) as well as for the entire year (c) compared to NDVI MOD09 (d), from 2013 to 2015.

For comparison of cloud masks (MODIS and MSG) it is necessary to consider that the daily MOD09 cloud mask product has a spatial resolution of $1 \mathrm{~km}$ while the MSG cloud mask 3 $\mathrm{km}$. Thus, for each MSG pixel analyzed the percentage of MOD09 pixels with clouds that are located in the same area. MOD09 cloud cover categories were created, related to cloud cover percentage within the MSG pixel area: very high (greater than $75 \%$ ), high (between $75 \%$ and $50 \%$ ), medium (between 50\% and 25\%) and low (less than $25 \%$ ). The Figure 3 shows the monthly and average percentage of MOD09 cloud mask cloud cover categories for pixels marked as cloud free (right) and cloud covered (left) by the MSG cloud mask.

To evaluate the results of geometric (BRDF) and atmospheric (6S) corrections results of NDVI MSG, the option was to present the correlation with the MOD09 daily reflectance product of 16 days MOD13 $250 \mathrm{~m}$ and within spatial resolution at $3 \mathrm{~km}$, having redesigned, the data, for this, using cubic convolution and resampling to $3 \mathrm{~km}$. Statistical analysis is shown in Figure 4 using the dispersion diagram of NDVI MOD13 in relation to NDVI MSG in the period 2013-2015: (a) without geometric and atmospheric correction; (b) with geometric correction (BRDF); (c) with atmospheric correction $(6 \mathrm{~S})$; and (d) with atmospheric (6S) and geometric (BRDF) correction. 
Revista Brasileira de Geografia Física, Vol. 13,n. 05 (2020) 2304-2318.
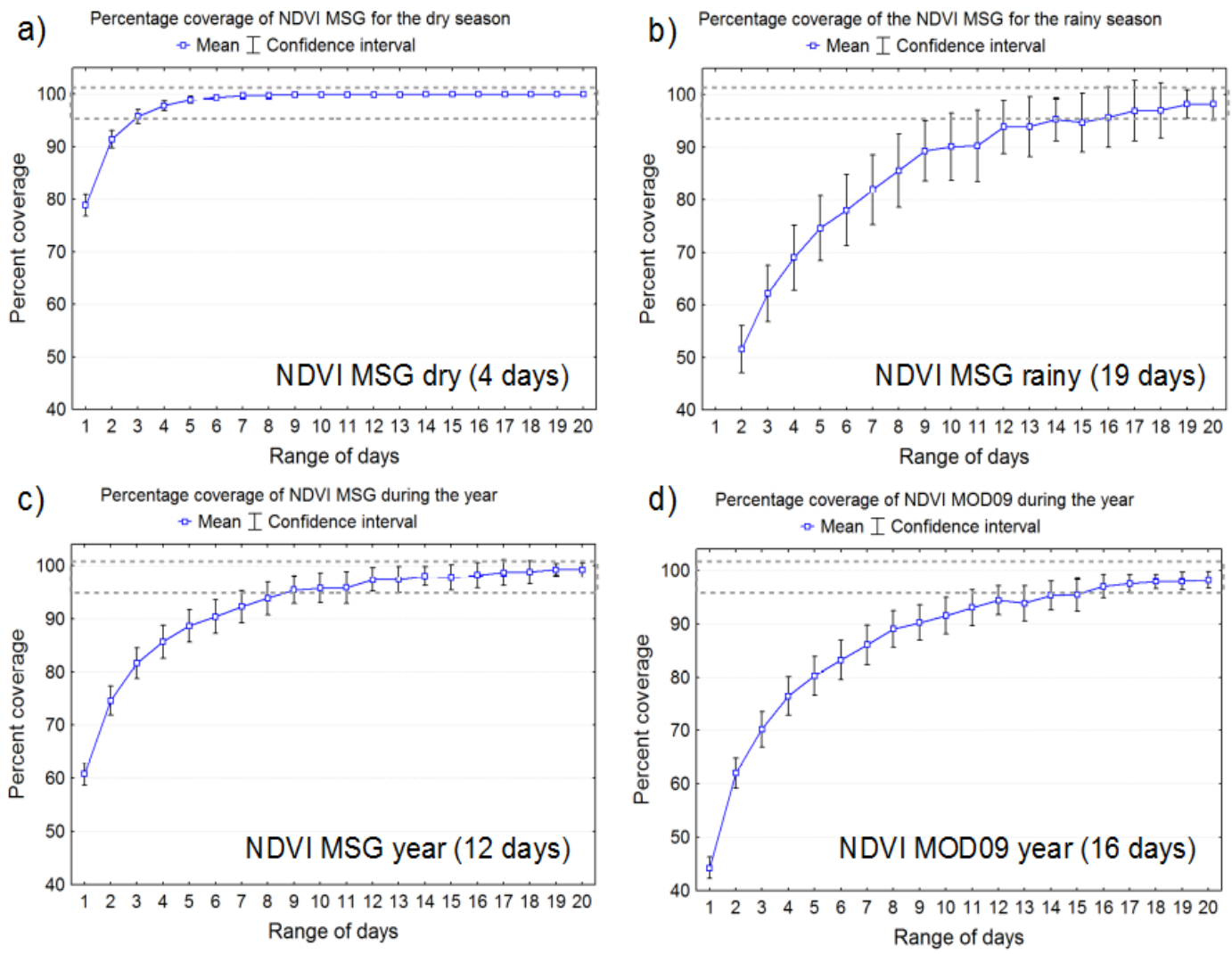

Figure 2. Percentage of coverage at 1 to 20 day intervals for NDVIMSG during drought (a) and rain (b) period, as well as for the whole year (c) compared to NDVI MOD09 (d) from 2013 to 2015 . Rectangles (in blue) are over the high coverage area (greater than $95 \%$ ).

a)

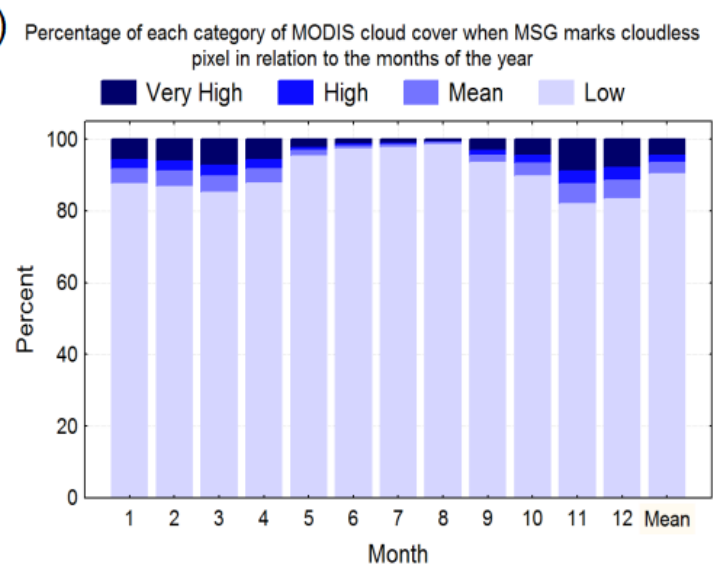

b)

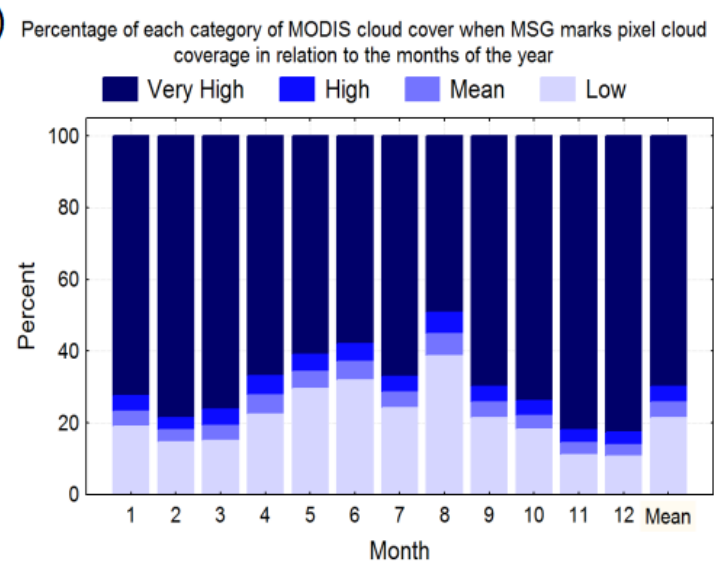

Figure 3. MSG and MODIS Cloud Mask Comparison (MOD09) for pixel conditionsmarked as cloudless (left) and clouded (right) for MSG. For MODIS data, pixels within the MSG pixel areaare considered and the values have been divided into the following MODIS product cloud coverage categories: very high (greater than 75\%), high (between 75\% and 50\%), medium (between 50\% and 25\%) and low (less than 25\%), in the months and years 2013-2015 for the study area. 
a)

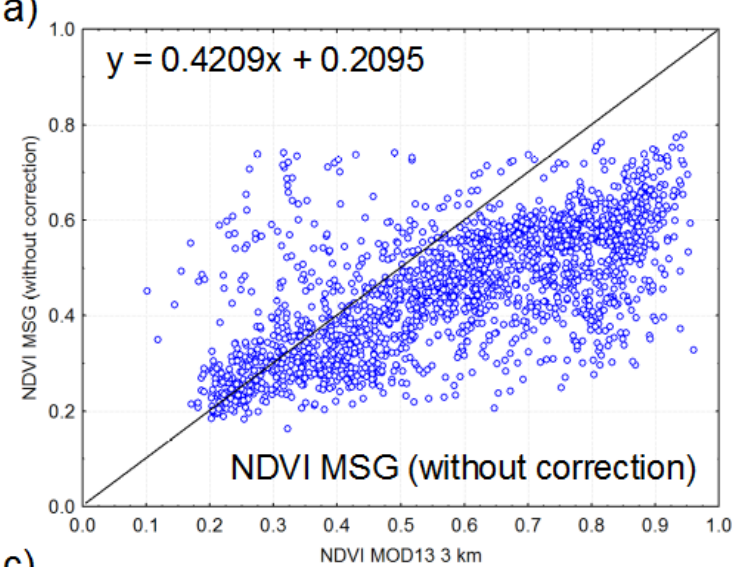

c)

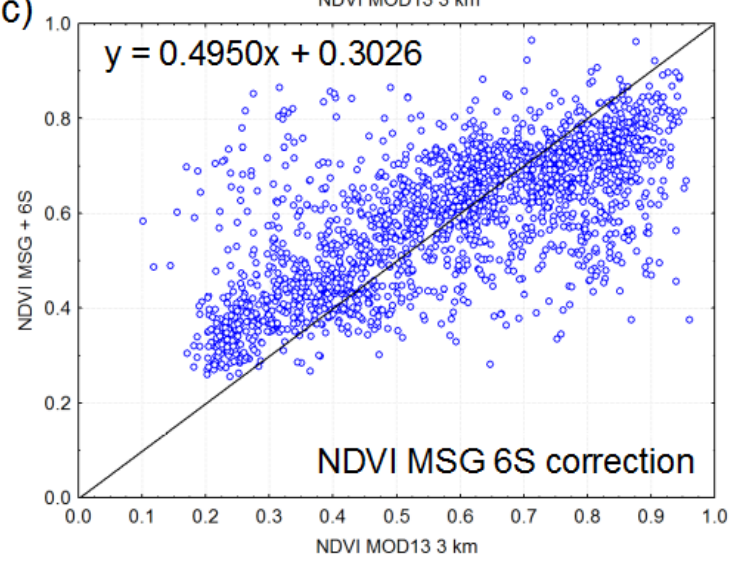

b)

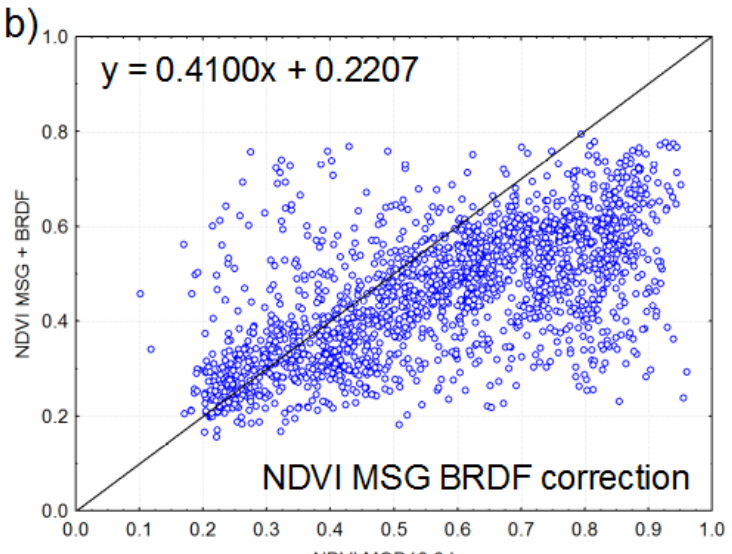

d)

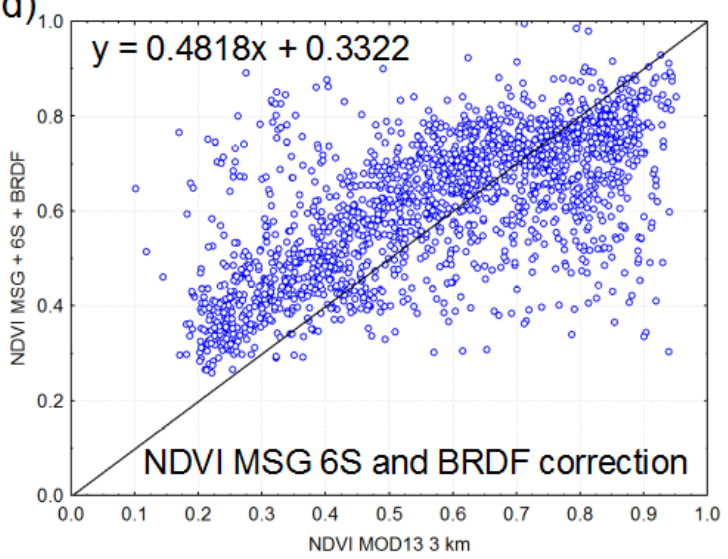

Figure 4. NDVI MOD13 dispersion diagram in relation to NDVI MDG, the data being redesigned using cubic convolution and resampled to $3 \mathrm{~km}$, without geometric and atmospheric correction (a), with geometric correction (BRDF) (b), with atmospheric correction (6S) (c) and with atmospheric correction (6S) and geometric (BRDF) (d) in the period 2013-2015.

Time series are shown in Figure 5, onepixel time series of annual agriculture and pasture for the NDVI MSG in the different correction combinations. Data normality was confirmed with the Shapiro-Wilk test. It is observed that the correlation value of the uncorrected NDVI MSG ( $\mathrm{r}$ $=0.77$ ) is lower than the value of the NDVI MSG $10: 00$ to $12: 00 \mathrm{~h}(\mathrm{r}=0.81)$. This is possibly due to the smaller sample size caused by the geometric correction algorithm that requires a minimum number of samples on the cloudless day or the numerical inversion process failure (Silveira et al., 2017).

For demonstrate the composition of images within 12 days, Figure 6 shows the NDVI MSG resulting from the evaluated techniques, being
NDVI MSG without techniques (a), geometric correction (b) or atmospheric correction (c).

As part of the analysis and in order to evaluate the influence of clouds on NDVI MSG (Figure 7) and NDVI MOD13 (Figure 8) product images, shows a time series of rainy months for 2013. The influence of the clouds is observed, where in the images the pixel has no data (black color).

For the operation of major components, the average was calculated for each range, resulting in an image with a number of bands corresponding to the number of images in a year. The first three components together represented almost every variance of the data $(99.6 \%$ for MSG and $99.1 \%$ for MODIS) (Figure 9). 
a)

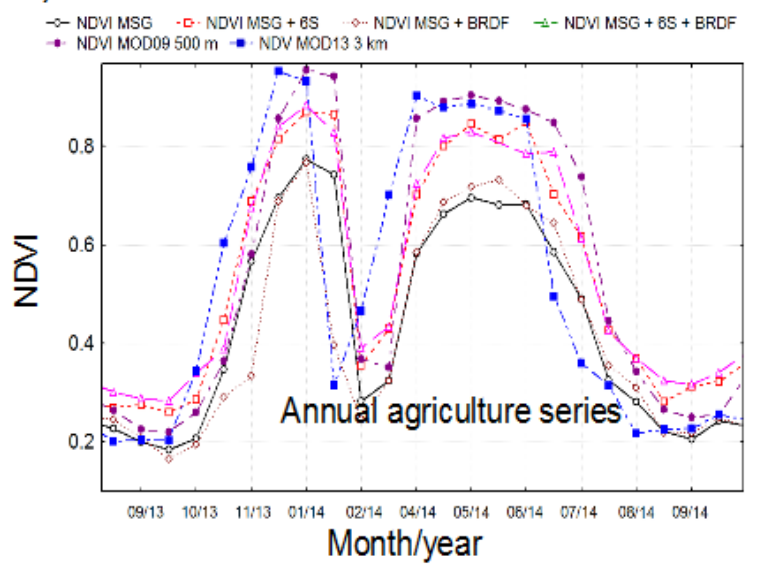

b)

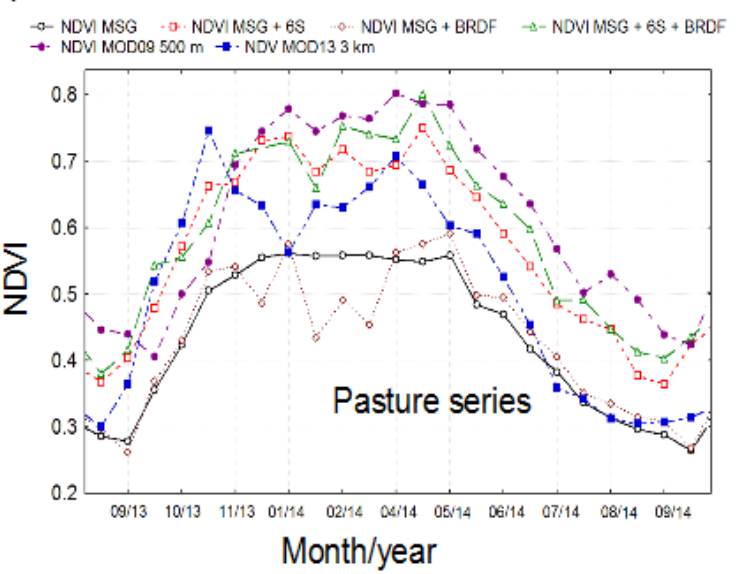

Figure 5. Annual agriculture time series (left), located in the municipality of Rio Verde, and pasture (right), located in the municipality of Mundo Novo, for the NDVI MSG (with or without corrections) and the NDVI MOD09 and MOD13. redesigned data using cubic convolution and resampled to $3 \mathrm{~km}$ for the period 09/2013 to $09 / 2014$. The abbreviations $6 \mathrm{~S}$ were used for atmospheric correction and BRDF for geometric correction.

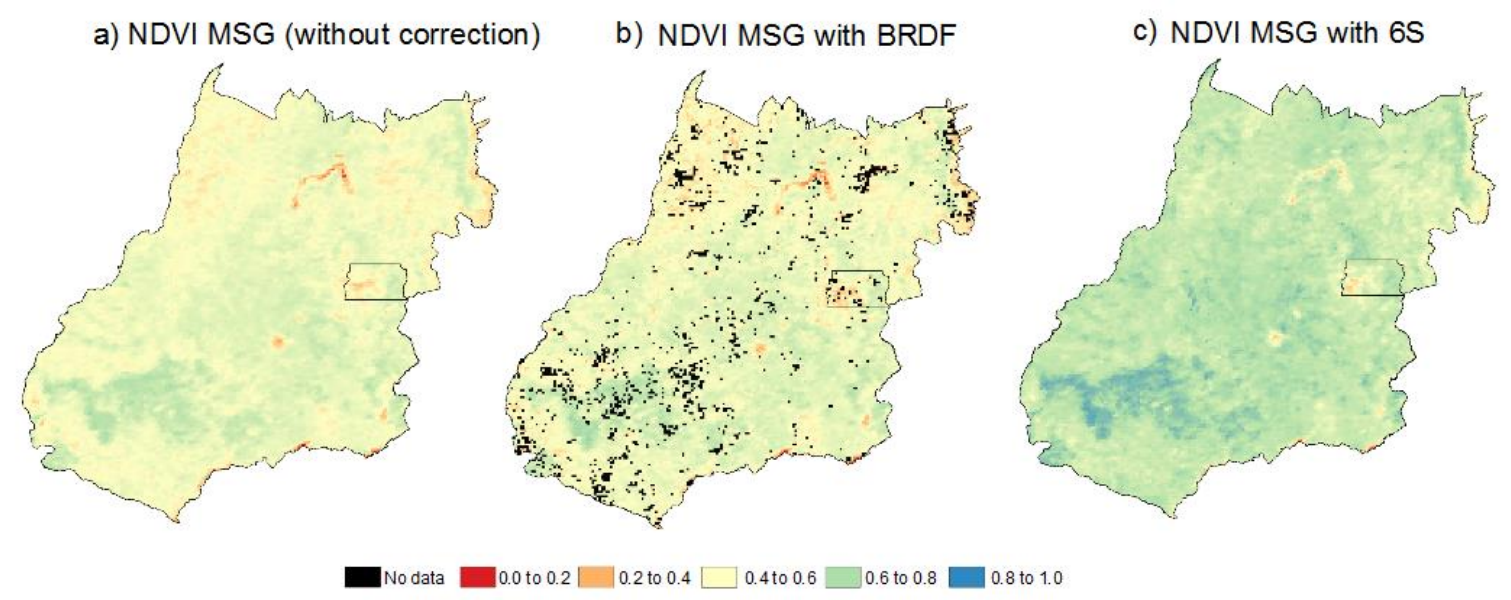

Figure 6. Composite images in the 12-day period (01/01/2013 to 13/01/2013) of NDVI MSG without applying techniques (a), geometric correction (b) or atmospheric correction (c).

In order to identify which class resulting from the k-means algorithm is related to which soil use class, a comparative analysis of the proportion of the classes of images resulting from the k-means technique (MSG and MOD13) with the main classes of soil use TerraClass 2013 was performed. To this end, the map was resampled to the most frequently found value of the MSG pixel area and redesigned and resampled to $3 \mathrm{~km}$.
The distribution of the study area pixels, in percentage of TerraClass 2013 classes, given classes obtained with the k-means algorithm for the first three main components of MSG and MODIS. With the identified classes a comparative analysis was made, using, for this, confusion matrix analysis and the Kappa agreement index, as shown in Figure 10. 
Revista Brasileira de Geografia Física, Vol. 13, n. 05 (2020) 2304-2318.
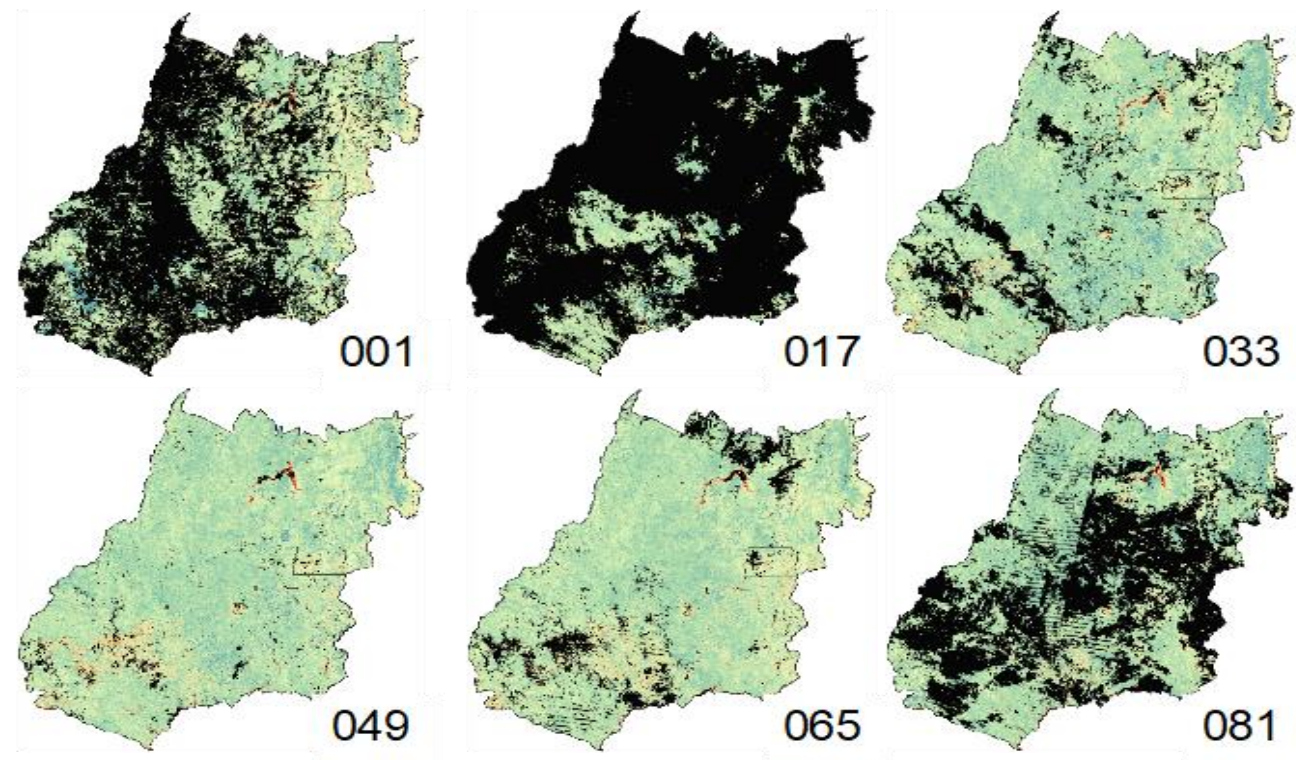

NO DATA $\square 0.0-0.2$

$0.2-0.4 \square \mid 0.4-0.6$

$0.6-0.8$

$0.8-1.0$

Figure 7. NDVI MSG time series at intervals of 12 days, in months of rainy season. The code in the lower right corner of each image corresponds to the initial doy (day of the year) of the composition, the data is from 2013. Were applied cloud filters to both products using the cloud mask product.
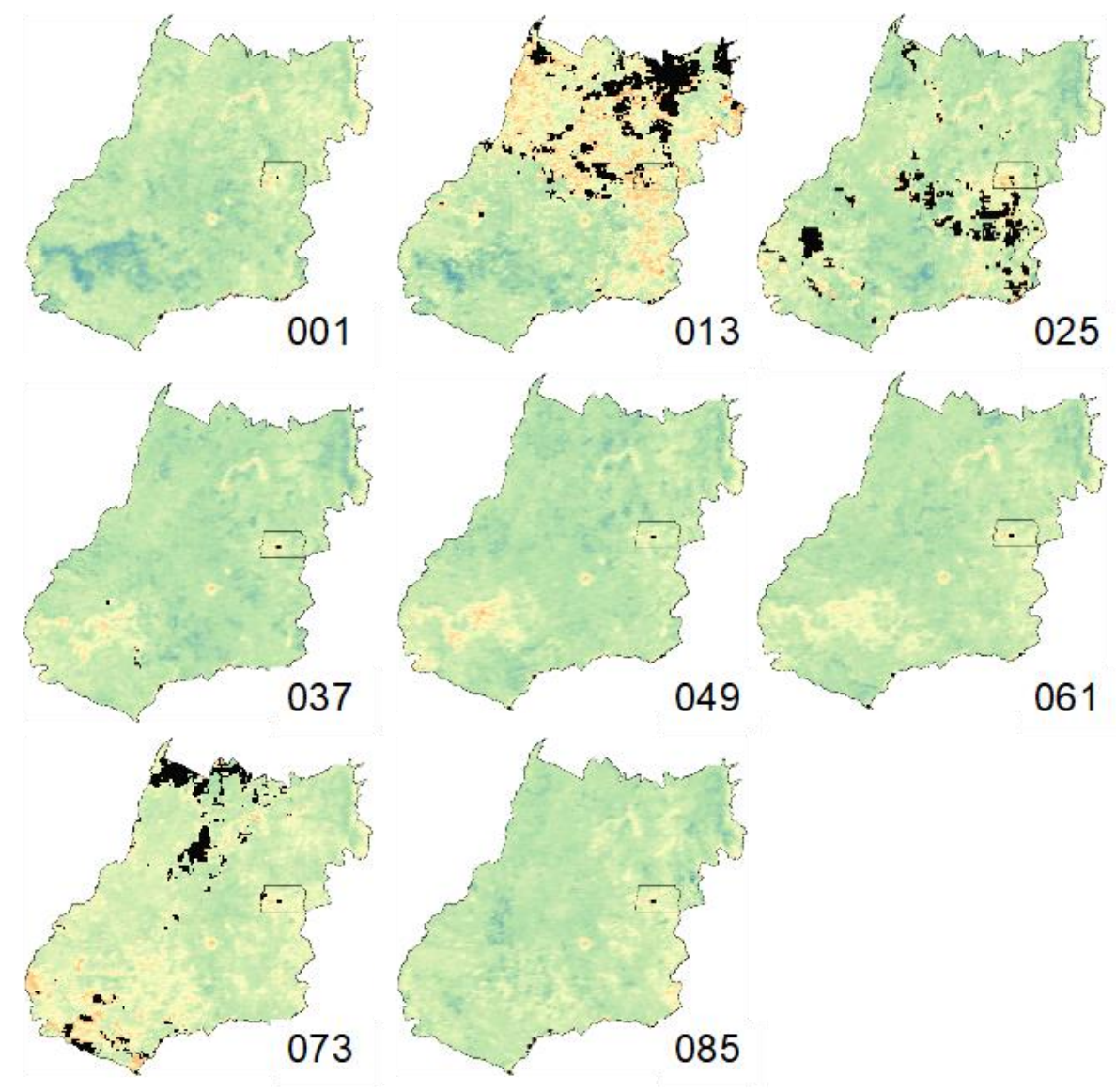

NO DATA

$0.0-0.2 \square 0.2-0.4 \square$

$0.4-0.6 \square 0.6-0.8$

$0.8-1.0$

Figure 8. NDVI MOD13 time series at interval of 16 days, in months of rainy season. The code in the lower right corner of each image corresponds to the initial doy (day of the year) of the composition, the data is from 2013. Were applied cloud filters to both products using pixel reliability, considering only high quality pixels. 
Revista Brasileira de Geografia Física, Vol. 13, n. 05 (2020) 2304-2318.
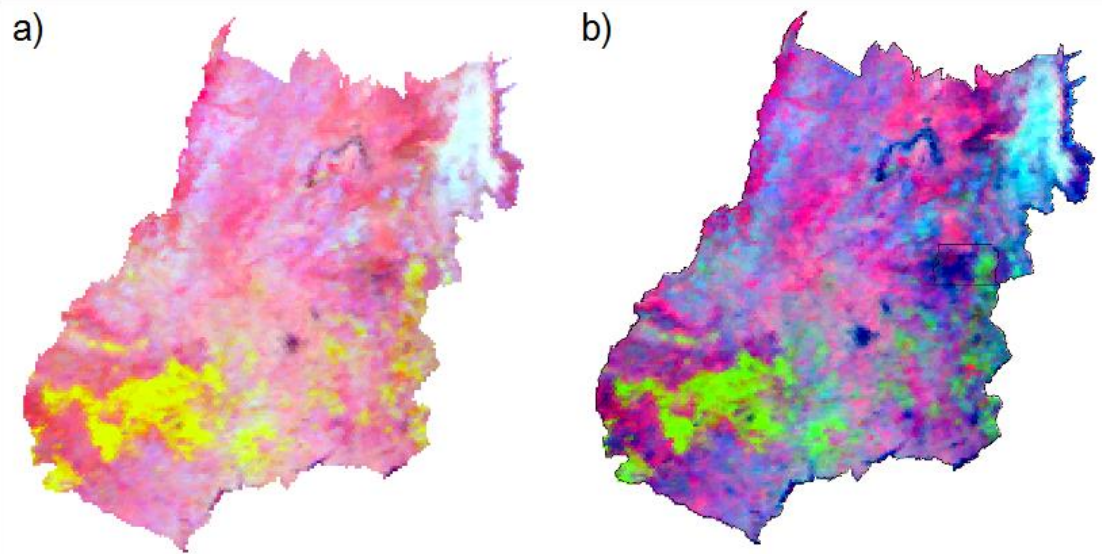

Figure 9. Image of the first three major components for MSG (a) and MOD13 (b) being represented in three bands PC1 (red color), PC2 (green color) and PC3 (blue color).
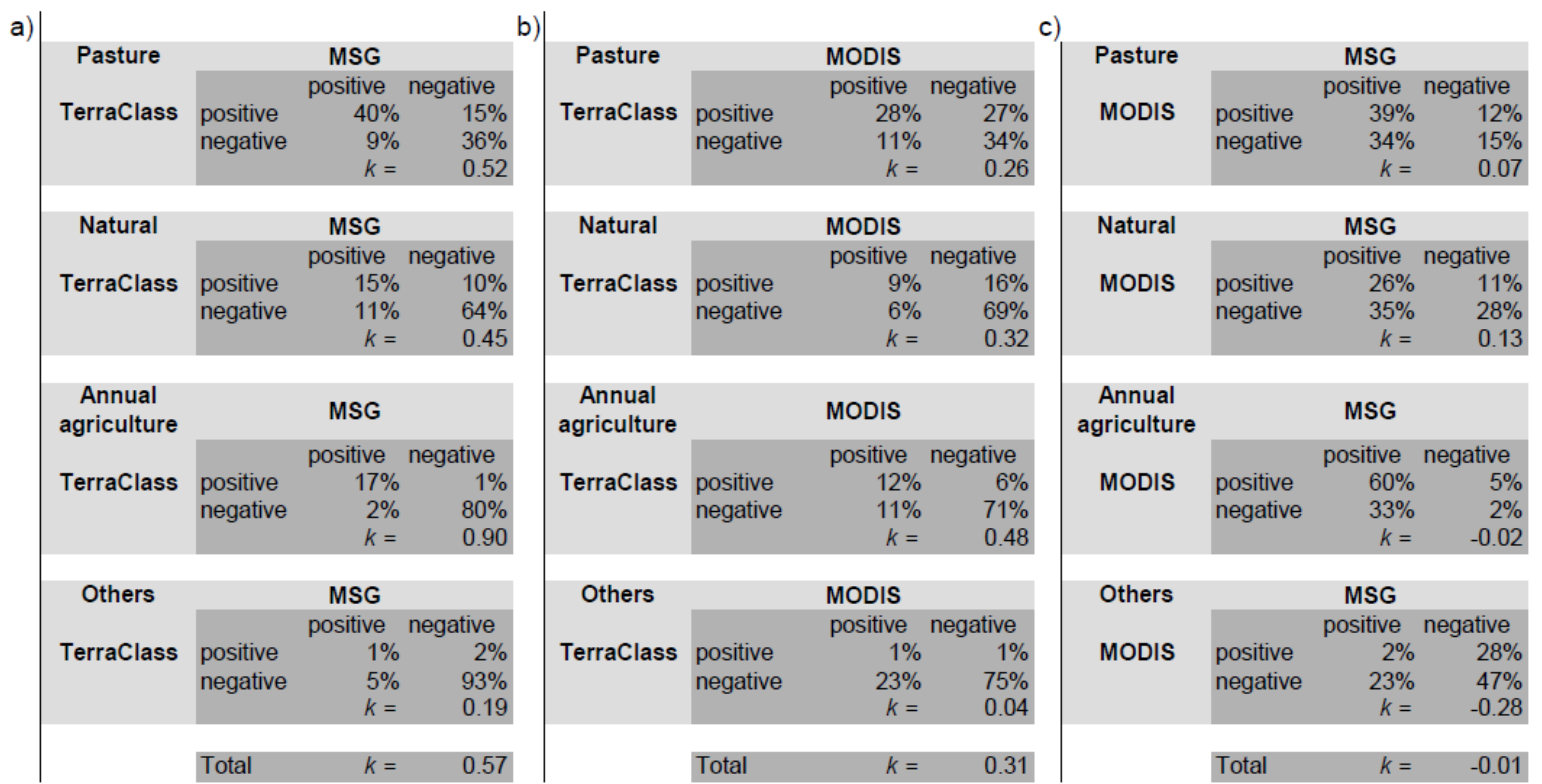

Figure 10. Correlation matrices of the main Terraclass 2013 classes with MSG (a), MODIS (b) and between MODIS and MSG (c), organized in columns. Being $100 \%$ the total pixels for the study area.

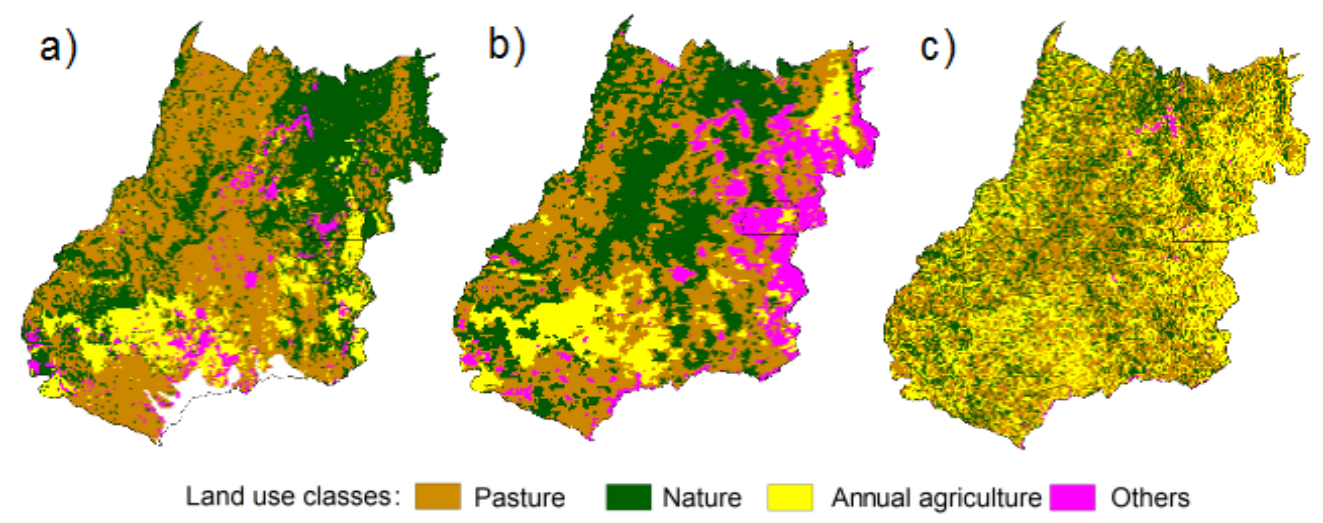

Figure 11. Map of the main land use classes of the redesigned TerraClass 2013 study area and resampling to 3 $\mathrm{km}$ (a) and results obtained from processing principal component and k-mean techniques with MSG (b) and MOD13 (c) data, for the period 2013-2015. 


\section{Discussion}

In assessing the day intervals for obtaining high coverage imaging (confidence interval above 95\%) MSG demonstrated higher temporal resolution (12 days) compared to MOD09 (16 days) (Figure 2-c, d). The MOD09 product over a 16 day period can obtain up to 16 observations; however, due to high cloud coverage at the time the sensor proceeds the readings, the average sample size becomes very small (Solano et al., 2015). The NDVI MSG interval is slightly larger than the range found by Fensholt et al. (2006), which was 10 days for the African continent, but has a smaller angle of view when compared to the study area in Brazil. Looking separately at NDVI MSG coverage for the dry (Figure 2-a) and rainy (Figure 2-b) seasons, it is clear that in the dry season the interval is really short (four days), however, in the rainy season, the interval is much longer (19 days).

The difference is more understandable in the analysis of cloud masks (Figure 3), when the MSG Cloud Mask marks the pixel as cloud-free, the MOD09 Cloud Mask has a high monthly average with low cloud content (greater than 90\%), varying according to seasonality, similar that Shang et al. (2018), in this study, cloud discrimination over the Tibetan Plateau is analyzed by the MODIS and AHI (Advanced Himawari Imager) sensors in Himawari-8 new-generation geostationary satellite data. In general, the error when the MSG cloud mask marks cloud free and the MOD09 mask considers high amount of clouds is small (less than 5\%).

However, when the MSG pixel has cloud coverage, MOD09 has a considerable monthly average with low cloud coverage (21\%), in fact, this error is mainly due to the high angle of view because some combinations of viewing geometry and lighting result in less reliable information as a cloud indicator, generating commission error, as observed in results similar to those found with the MSG in other areas of high viewing angle (Proud et al., 2014). Consequently, the definition of a shorter range of days to obtain NDVI MSG with high coverage over the study area is impaired due to cloud detection algorithm commission errors (on average $21 \%$ ).

The atmospheric correction maintains or increases the correlation of NDVI MSG compared to NDVI MOD09 or MOD13, different from the geometric correction which decreases the correlation between the data (Figure 4). Similarly, observing the time series (Figure 5), the NDVI MOD13 and MOD09 values are relatively higher than the uncorrected NDVI MSG. However, this difference is smaller for NDVI MSG with atmospheric correction making the values closer to NDVI MOD13 $3 \mathrm{~km}$, regardless of the class of soil use.

On the other hand, the geometric correction provided a fine adjustment of the source values that did not generate a relevant change in the original time series (Figure 5), demonstrating that this procedure can improve the correlation of NDVI MSG data with NDVI MOD13. However, as the MSG is geostationary, the viewing angle is the same for any sample of the day, in fact, the pixel area is not observed at different viewing angles, not meeting a quality requirement of the geometric correction methods (Han et al., 2018; Seong et al., 2020), as seen on not calculated pixels in BRDF correction (Figure 6c), if calculated, could aggregate information for the numerical inversion process and thus improve the results of geometric correction (Fensholt et al., 2006; Silveira et al., 2017). Furthermore, it would be useful if the kernels responded to the large variation in solar position, and large number of geostationary satellite observations would help to evaluate and improve the BRDF model in combination with the data from polar-orbiting satellites, as soon as observed by Matsuoka et al. (2016) that studied BRDF geometric correction in bands RED and NIR to obtain NDVI index using Himawari-8 geostationary satellite.

Thus, only atmospheric correction was used to obtain the 12-day NDVI MSG composition. It is observed that the product MOD13 has greater data absence than the MSG, mainly in the first two images (Figure 7, doys 001 and 017). Specifically in the southwest region, where there is a predominance of land use for annual agriculture, cloud cover occurs during most of the evaluated period (Figure 8, excluding doy 049), making it difficult to monitor with NDVI MOD13, unlike MSG, which showed greater cloud influence on only one image (Figure 9, doy $025)$. Thus, with the greater coverage of NDVI MSG data on agricultural areas, it is possible to monitor crops allowing the identification of the stages of crop development (Julien et al., 2018).

The visual result of the PCA technique for the MSG and MOD13 (Figure 9) compared to the Terraclass Map 2013 (Figure 11-a) allows us to identify areas with similar large patterns, such as in southwestern Goiás and the eastern boundaries of the state (in MSG (left) in yellow and MOD13 (right) in green), which corresponds to agricultural areas, and in the northeast of the state, which 
Revista Brasileira de Geografia Física, Vol. 13, n. 05 (2020) 2304-2318.

presents a differentiated pattern (in the gray-white MSG (left) and MOD13 (right) in light blue) and which corresponds mainly to pasture areas.

Analyzing the results of the unsupervised k-means classification algorithm (Figure 10) MSG provides a better ranking among the main TerraClass 2013 classes (68\% pasture, $53 \%$ natural and $83 \%$ annual agriculture) compared to the MOD13 product (50\% pasture, $46 \%$ natural and $72 \%$ annual agriculture). The levels of agreement are for the substantial MSG for annual agriculture $(\mathrm{K}=0.73)$ and considerable for pasture $(\mathrm{K}=0.35)$ and natural $(\mathrm{K}=0.34)$, unlike MODIS which has a considerable level of agreement. for annual $(\mathrm{K}=$ $0.29)$ and natural $(K=0.32)$ and light for pasture $(\mathrm{K}=0.06)$ agriculture. Better results are observed with the annual agriculture class, compared to the other evaluated classes, this is related to the annual seasonality of two agricultural cycles, first phase and second phase (Figure 5-a), which is different from pasture seasonality (Figure 5-b) and natural vegetation. This difference is noticeable in the images of the main components (Figure 9) that allow us to distinguish the southwest region of the state of Goiás, which has a predominance of annual agriculture. This results are similar Miura et al. (2019) that used Himawari-8 AHI sensor to obtain NDVI temporal signatures that capture seasonal changes in vegetation and snow cover in finer detail with more certainty than those obtained from Visible Infrared Imaging Radiometer Suite (VIIRS), one of the latest polar-orbiting satellite sensors.

In this analysis, a better result was expected for MODIS due to its lower spatial resolution compared to MSG. However, when compared to related studies on the use of unsupervised land use classification techniques uses large time series (20 - 30 years) and in this the time series was small (Almeida et al., 2015; Barbosa et al., 2019). On the other hand, it is necessary to consider that the NDVI MOD13 product, when filtered the influences of clouds, has less coverage over the study area than the NDVI MSG product, as can be seen in images of the rainy months in 2013 (Figure 7). Such results demonstrate the capacity for unsupervised classification of series time constraints and, to a certain extent, the potential for geostationary satellite data for surface monitoring, by providing data in shorter time intervals, when compared to polar orbit satellites, even when using time series short.

The visual assessment of the maps shows large patterns of land use classes in the Terraclass 2013 images (Figure 11-a) that can be seen in the
MSG (Figure 11-b), but cannot be seen with the results of the MOD13 (Figure 11-c) as areas of annual agriculture and pasture in the southwest, pasture in the northwest and natural vegetation in the north-central area. Similarly, the large pasture and natural areas of northern Goiás are seen in the MSG, however, when comparing with TerraClass 2013 it is clear that errors of commission and omission occur between the two classes. In addiction, to some extent, this error is common in unsupervised classification, mainly due to soil coverage characteristics in this area, where the natural landscape is predominantly savannah formations, which have similar seasonal patterns to pasture. Class "other" in MSG can include several classes of the Terraclass 2013 map such as urban areas, bodies of water, forestry, unobserved. However, it also includes other areas such as border areas northeast of the state of Goiás, possibly because they have a distinct seasonal pattern from other classes (agriculture, pasture and natural).

\section{Conclusion}

This article aimed to evaluate the achievement of quality NDVI MSG at high viewing angles, having as study area the state of Goiás, Brazil, from 2013 to 2015. The interval during the day that showed the best result was from 10:00 am to $12: 00 \mathrm{pm}$, in a comparative analysis, NDVI MSG was able to obtain images of the state of Goiás with high pixel coverage $(95 \%)$ in the interval of 12 days, while MOD09 obtains in the interval of 16 days. However, the cloud mask of the MSG, compared to the cloud mask of the MOD09 product, hits more when it marks pixel as free of clouds (90\%) than when it marks the pixel as cloud (70\%), being, in this case, relevant to error percentage of the MSG pixel where MOD09 pixels mark the area as cloud-free $(21 \%)$. Thus, the opportunity to have an image with high coverage in a shorter interval of days is impaired due to errors of commission of presence of clouds by the product cloud mask. Anyway, the higher temporal resolution allows to obtain a larger sample for time series analysis, adding more information to the analyzes.

The geometric correction is a fine adjustment that, in these analyzes, did not show an increase in the correlation of the data. On the other hand, the atmospheric correction maintains the correlation of the data and increases the NDVI value, bringing the NDVI MSG value closer to NDVI MODIS products.

When performing a PCA analyses with MSG and MODIS data, it is clear that the products 
can abstract patterns of seasonality of soil use. However, in unsupervised classification, it is possible to notice the differential of geostationary satellites for classification of the main classes of soil usage, because even in a short time series, it presented results of substantial agreement for annual and considerable pasture and natural agriculture. Demonstrating that the increase of temporal resolution, due to the smaller interval between observations, provides greater capacity for abstraction and differentiation of seasonality.

This study allowed a better understanding of geostationary orbit satellite data to obtain vegetation index, specifically NDVI, presenting characteristics, techniques and operations that can provide a higher quality product, as well as evaluating the application potential in monitoring the soil surface. This study can be expanded to obtain vegetation indices by other geostationary satellites, such as the GOES and Himawari series.

\section{Acknowledgment}

Thanks to FAPEG (Foundation for Support to Research in State of Goiás) by granting $\mathrm{PhD}$ Scholarship of the edict $\mathrm{n}^{\circ} 03 / 2014$ case \# 201410267000416, the IFG (Federal Institute of Goiás), for their support in the development of research and LAPIG (Image Processing and GIS Lab) for all support and referential.

\section{References}

Almeida, T.I.R.; Penatti, N.C.; Ferreira, L.G.; Arantes, A.E.; Amaral, C. H., 2015. Principal component analysis applied to a time series of MODIS images: the spatio-temporal variability of the Pantanal wetland, Brazil. Wetlands Ecology and Management [online] 23. Disponible in: https://doi.org/10.1007/s11273015-9416-4. Access: 23 mar. 2020.

Barbosa, H.A., Kumar, T.V.L., Paredes, F., Elliott, S., Ayuga, J.G., 2019. Assessment of Caatinga response to drought using Meteosat-SEVIRI Normalized Difference Vegetation Index (20082016). ISPRS Journal of Photogrammetry and Remote Sensing [online] 148. Disponible in: https://doi.org/10.1016/j.isprsjprs.2018.12.014. Access: 23 mar. 2020.

Cao, R., Chen, Y., Shen, M., Chen, J., Zhou, J., Wang, C., Yang, W., 2018. A simple method to improve the quality of NDVI time-series data by integrating spatiotemporal information with the Savitzky-Golay filter. Remote Sensing of Environment [online] 217. Disponible in: https://doi.org/10.1016/j.rse.2018.08.022.

Access: 23 mar. 2020.
Cohen, J., 1960. A coefficient of agreement for nominal scales. Educational and Psychological Measurement [online] 20. Disponible in: https://doi.org/10.1177/001316446002000104. Access: 23 mar. 2020.

Cracknell, A.P., 1998. Review article Synergy in remote sensing what's in a pixel? International Journal of Remote Sensing [online] 19. Disponible https://doi.org/10.1080/014311698214848. Access: 23 mar. 2020.

Fensholt, R., Anyamba, A., Huber, S., Proud, S.R., Tucker, C. J., Small, J., et al., 2011. Analysing the advantages of high temporal resolution geostationary MSG SEVIRI data compared to Polar Operational Environmental Satellite data for land surface monitoring in Africa. International Journal of Applied Earth Observation and Geoinformation [online] 13. Disponible https://doi.org/10.1016/j.jag.2011.05.009.

Access: 23 mar. 2020.

Fensholt, R., Sandholt, I., Stisen, S., Tucker, C., 2006. Analysing NDVI for the African continent using the geostationary meteosat second generation SEVIRI sensor. Remote Sensing of Environment [online] 101. Disponible in: https://doi.org/10.1016/j.rse.2005.11.013.

Access: 23 mar. 2020.

GDAL. Geospatial Data Abstraction Library. Disponible in: http://www.gdal.org/. Access: 23 mar. 2020.

GomesDans, J., 2015. BRDF modelling with python and MODIS data. Disponible in: https://jgomezdans.github.io/brdf-modelling-ofmodis-land-surface-data.html. Access: 23 mar. 2020.

Han, L., Yang, S., Cui, S. and Lu, W., 2018. Impact of different BRDF models on the inversion of desert surface emissivities, Proc. SPIE 10697, Fourth Seminar on Novel Optoelectronic Detection Technology and Application. Disponible in: https://doi.org/10.1117/12.2315472. Access: 23 mar. 2020.

Hubanks, P., Patnick, S., King, M., Ridgway, B., 2016. MODIS Atmosphere L3 Gridded Product Algorithm Theoretical Basis Document (ATBD) \& Users Guide. Disponible in: https://modisimages.gsfc.nasa.gov/_docs/L3_ATBD_C6.pdf. Access: 23 mar. 2020.

IBGE. Instituto Brasileiro de Geografia e Estatística, 2002. Mapa Clima Brasil. Disponible in:

https://www.ibge.gov.br/geociencias/informacoe s-ambientais/climatologia/15817- 
Revista Brasileira de Geografia Física, Vol. 13, n. 05 (2020) 2304-2318.

clima.html?=\&t=acesso-ao-produto. Access: 27 mar. 2020.

Jones, H.G., Vaughan, R.A., 2010. Remote sensing of vegetation: principles, techniques and applications, 1. ed.Oxford University Press, New York.

Julien, Y., Sobrino, J.A., Jiménez-Muñoz, J.-C., Sória, G., Skokovic, D., Gomis-Cebolla, J., Garcia Monteiro, S., 2018. Using MSG-Seviri Data to Monitor the Planet in Near Real Time. In: IGARSS 2018 - 2018 IEEE International Geoscience and Remote Sensing Symposium, Valencia, Spain. Disponible in: https://doi.org/10.1109/IGARSS.2018.8518647. Access: 23 mar. 2020.

Kotchenova, S.Y., Vermote, E.F., 2007. Validation of a vector version of the $6 \mathrm{~S}$ radiative transfer code for atmospheric correction of satellite data. Part II. Homogeneous Lambertian and anisotropic surfaces. Applied Optics [online] 46. Disponible in: https://doi.org/10.1364/AO.45.006762. Access: 23 mar. 2020.

Kotchenova, S.Y., Vermote, E.F., Levy, R., Lyapustin, A., 2008. Radiative transfer codes for atmospheric correction and aerosol retrieval: intercomparison study. Applied Optics [online] $47 . \quad$ Disponible in: https://doi.org/10.1364/AO.47.002215. Access: 23 mar. 2020.

Lee, C.S., Yeom, J.M., Lee, H.L., Kim, J. J., Han, K.S., 2015. Sensitivity analy sis of 6 S-based lookup table for surface reflectance retrieval. AsiaPacific Journal of Atmospheric Sciences [online] 51.Disponible

https://doi.org/10.1007/s13143-015-0062-9. Access: 23 mar. 2020.

Macqueen, J.B., 1967. Some methods for classification and analysis of multivariate observations. In: Berkeley Symposium on Mathematical Statistic and Probability. Proceedings... Berkeley, California. Disponible in:

https://projecteuclid.org/euclid.bsmsp/12005129 92. Access: 23 mar. 2020.

Matsuoka, M., Takagi, M., Akatsuka, S., Honda, Rie, A., Nonomura, A., Moriya, H., Yoshioka, H., 2016. Bidirectional reflectance modeling of the geostationary sensor Himawari-8/AHI using a kernel-driven BRDF model. IN: ISPRS Annals of Photogrammetry, Remote Sensing and Spatial Information Sciences. Proceedings... Prague, Czech Republic. Disponible in: https://doi.org/10.5194/isprs-annals-III-7-32016. Access 27 mar. 2020.
Miura, T., Nagai, S., Takeuchi, M., Ichii, K., Yoshioka, H., 2019. Improved Characterisation of Vegetation and Land Surface Seasonal Dynamics in Central Japan with Himawari-8 Hypertemporal Data. Scientific Report[online]9. Disponible in: https://doi.org/10.1038/s41598019-52076-x. Access: 23 mar. 2020.

MMA. Ministério do Meio Ambiente, 2015. Mapeamento do Uso e Cobertura do Cerrado: Projeto TerraClass Cerrado, Brasília. Disponible in:

https://www.mma.gov.br/biomas/cerrado/projeto -terraclass.html. Access: 23 mar. 2020.

Proud, S.R., Fensholt, R., Rasmussen, M. O., Sandholt, I., 2010. A comparison of the effectiveness of $6 \mathrm{~S}$ and SMAC in correcting for atmospheric interference of Meteosat Second Generation images. Journal of Geophysical Research [online] 115. Disponible in: https://doi.org/10.1029/2009JD013693. Access: 23 mar. 2020.

Proud, S.R., Schaaf, C., Fensholt, R., Rasmussen, M.O., Shisanya, C., Mutero, W., et al., 2014. The Normalization of Surface Anisotropy Effects Present in SEVIRI Reflectances by Using the MODIS BRDF Method. IEEE Transactions on Geoscience and Remote Sensing [online] 52. Disponible https://doi.org/10.1109/TGRS.2013.2294602. Access: 23 mar. 2020.

Qu, Y., Liu, Q., Liang, S., Wang, L., Liu, N., Liu, S., 2014. Direct-estimation algorithm for mapping daily land-surface broadband albedo from modis data. IEEE Transactions on Geoscience and Remote Sensing [online] 52. Disponible https://doi.org/10.1109/TGRS.2013.2245670. Access: 23 mar. 2020.

Ratana, P., Huete, A.R., Ferreira, L.G. 2005. Analysis of Cerrado Physiognomies and Conversion in the MODIS Seasonal-Temporal Domain. Earth Interactions [online] 9. Disponible in: https://doi.org/10.1175/10873562(2005)009<0001:AOCPAC > 2.0.CO;2.

Access: 27 mar. 2020.

Roujean J.-L., Leroy M., Deschamps P.-Y., 1992. A bidirectional reflectance model of the Earth's surface for the correction of remote sensing data. Journal of Geophysical Research [online] 97. Disponible in: https://doi.org/10.1029/92JD01411. Access 23 mar. 2020.

Sarr, M.A., Lacaze, B., 2008. Caractérisation de la dynamique de la végétation en Afrique de l'Ouest : comparaison des indices NDVI de MSGSEVIRI, SPOT-VEGETATION et NOAA- 
Revista Brasileira de Geografia Física, Vol. 13, n. 05 (2020) 2304-2318.

AVHRR (exemple du Ferlo, Sénégal). In Texte issu d'une communication au colloque Météosat Seconde Gération : un nouvel outil de suiv., p. 110. Disponible in: https://halshs.archivesouvertes.fr/halshs-00260971. Access: 23 mar. 2020.

Schaaf, C.B., Gao, F., Strahler, A.H., Lucht, W., Li, X., Tsang, T.; et al., 2002. First operational BRDF, albedo nadir reflectance products from MODIS. Remote Sensing of Environment [online] 83.8 Disponible: https://doi.org/10.1016/S0034-4257(02)00091-3. Access 23 mar. 2020.

Seong, N.H., Jung, D., Kim, J., Han, K.-S., 2020. Evaluation of NDVI Estimation Considering Atmospheric and BRDF Correction through Himawari-8/AHI. Asia-Pacific Journal of Atmospheric Sciences. Disponible in: https://doi.org/10.1007/s13143-019-00167-0. Access: 24 mar. 2020.

Shang, H., Letu, H., Nakajima, T.Y., et al., 2018. Diurnal cycle and seasonal variation of cloud cover over the Tibetan Plateau as determined from Himawari-8 new-generation geostationary satellite data. Scientific Reports [online] 8. Disponible in: https://doi.org/10.1038/s41598018-19431-w. Access: 24 mar. 2020.

Silveira, C.R., Ferreira, L.G., Silva, B.B., 2017. Análise da correção geométrica por meio de função de refletância bidirecional da superfície em dados de satélite geoestacionário. In: XVIII Simpósio Brasileiro de Sensoriamento Remoto. Proceedings... Santos, Brazil. Disponible in: https://proceedings.science/sbsr/autores/carlosroberto-da-silveira-junior. Access: 23 mar. 2020. Silveira, C.R., Ferreira, L.G., Silva, B.B., 2019. Characteristics and challenges of NDVI generation to Brazil from Meteosat-10 geostationary orbit satellite data. Revista Brasileira de Geografia Física [online] 12. Disponible in: https://doi.org/10.26848/rbgf.v12.3.p1142-1155. Access 23 mar. 2020.
Solano, R., Didan, K., Jacobson, A., Huete, A., 2015. MODIS Vegetation Index User's Guide (MOD13 Series). Disponible in: https://vip.arizona.edu/documents/MODIS/MO DIS_VI_UsersGuide_June_2015_C6.pdf.

Access: 23 mar. 2020.

Tucker, C.J., 1979. Red and Photographic Infrared Linear Combinations for Monitoring Vegetation. Remote Sensing of Environment [online] 150. Disponible in: https://doi.org/10.1016/00344257(79)90013-0. Access: 23 mar. 2020.

Vermote, E.F., Tanre, D., Deuze, J.J., Herman, M., Morcrette, J., Kotchenove, S. Y., 2006. Second Simulation of a Satellite Signal in the Solar Spectrum - Vector (6SV), 6S user guide. Disponiblein: http://6s.ltdri.org/. Access: 23 mar. 2020.

Vermote, E.F., Tanre, D., Deuze, J.L., Herman, M., Morcrette, J.-J., 1997. Second Simulation of the Satellite Signal in the Solar Spectrum, 6S: An Overview. IEEE Geoscience and Remote Sensing [online] $35 . \quad$ Disponible in: https://doi.org/10.1109/36.581987. Access: 23 mar. 2020.

Wanner, W.; Li, X.; Strahler, A.H., 1995. On the derivation of kernel for kernel-driven models of bidirectional reflectance. Journal of Geophysical Research [online] 100. Disponible in: DOI: https://doi.org/10.1029/95JD02371. Access: 23 mar. 2020.

Wilson, R.T., 2013. Py6S: A Python interface to the $6 \mathrm{~S}$ radiative transfer model. Computers and Geosciences [online] 51. Disponible in: https://doi.org/10.1016/j.cageo.2012.08.002.

Access: 23 mar. 2020. 